\title{
On Writer's Block: The Reflection of Lacanian Post-Structuralist Psychoanalysis in Paul Auster's Oracle Night
}

\author{
Maroš Buday \\ University of Prešov, Slovakia
}

This paper deals with the reflection of Lacanian post-structuralist psychoanalysis in Paul Auster's novel Oracle Night, with respect to the phenomenon of writer's block. The paper argues that Auster's novel is remarkably synchronized with the theoretical perspectives proposed by the noted psychoanalyst, Jacques Lacan, as the root of his protagonist's inability to write is linked to the medium of written discourse, and the obstacles which the protagonist of his story faces are thus put within the confines of the protagonist's psyche. Writer's block is thus being examined with respect to the Lacanian concept known as the chain of signification, as it is much more noticeable in writers because their primary conduit for describing the exterior and interior world is discourse in its written form. Auster exceptionally mirrors Lacan's view of a writer's psyche and vividly explores the foundation of the inability to write with respect to the symbolic realm of human experience.

\section{Keywords}

Jacques Lacan; Paul Auster; Oracle Night; writer's block; chain of signification

\section{Introduction}

Most people, irrespective of the fact whether they are ordinary people or writers, have, at some point in their lives, experienced the deeply unpleasant feeling of anxiety inexplicably and seemingly arising out of nowhere when getting stuck while putting what they want in writing. This feeling, which is, in small doses, quite common in the everyday life of a person, becomes much more than a simple nuisance when one is not able to articulate what $\mathrm{s} / \mathrm{he}$ wants for a prolonged period of time. Unsurprisingly, it is most pronounced 
in people who write for a living. The mocking blank page which every writer dreads is the starting point for a very complex phenomenon commonly known as "writer's block".

"Writer's block" is one those phrases, the meaning of which one intuitively seems to grasp. According to the most widely cited author on the subject, Rose (1984), writer's block is "an inability to begin or continue writing for reasons other than a lack of basic skill or commitment" (18). However, in psychological academic discourse, it is a phenomenon that has scarcely been sufficiently researched with respect to professional writers. Most of the research on writer's block in general focuses on students and their problems with writing essays and theses, and overcoming them. ${ }^{1}$ As Landman (2016) points out, "[a] range of, mostly US, studies [conducted on] undergraduates has found that writer's block and anxiety are both testable constructs, however the writer's voice has been absent in the research" (4).

Nevertheless, according to Rose's research, “writer's block is primarily a manifestation of low opinion of one's work and fear of evaluation" (76). Interestingly enough, as it is in the case of Rose, much of the research into the phenomenon of writer's block is limited to external factors that are the domain of behavioural psychology. There are very few articles or monographs exploring the concept of writer's block with respect to psychoanalysis, not to mention Lacanian psychoanalysis. The reason for this may be due to the difficulty of testing psychoanalytical or Lacanian theories in a practical setting. This very fact, however, may justify using Lacanian psycho-linguistic theories and models and applying them, not directly to writers, but to the next best thing, the writers' experience internalized in their fiction, which is exactly what this paper aims to do.

The present paper deals with the exploration of the phenomenon of writer's block as described in the writings of the noted French psychoanalyst Jacque Lacan, and depicted in one of the novels written by Paul Auster, Oracle Night (2003). It aims to shed some light on writer's block as understood by Paul Auster, who himself has gone through a prolonged period of stagnation when it came to writing ${ }^{2}$ and imparted his experience with the event in the aforementioned novel. The reason for including the teachings of Lacan in the analysis of Auster's novel is that Auster's work bears eerie similarities to Lacan's understating of anxiety brought on by one's inability to articulate the desired, mostly presented by his largely forgotten text, The Subversion of the Subject and the Dialectic of Desire in the Freudian Unconscious (1960). In it, Lacan delves deep into the problem of human articulation of the desired through the means of 
the model he calls "the chain of signification", which can be understood as the basis for the emergence of writer's block in the first place.

\section{Articulating the Desired}

When an average person wishes to express his/her want, according to Lacan, they go through a series of stages which are depicted in Lacan's vision of what he calls the chain of signification (figure 1) expressing the articulation of one's phallus. The following graph is divided into two parts. One of them is called the lower chain of signification and it is a natural way of peoples' articulation of human desires. Whatever a person wants to express, the object of desire is always first conceived in the unconscious mind. Even before a person is able to reveal his/her need, this need is always formulated within the recesses of one's subconscious beforehand. Because Lacan believed that the human unconscious is structured like language, it is imperative to understand that one's phallus (the thing which is desired to be articulated) is to be expressed chiefly within the realm of discourse.

Figure 1. Jacques Lacan, "The Subversion of the Subject and the Dialectic of Desire in the Freudian Unconscious." Ecrits: The First Complete Edition in English, Ed. Bruce Fink, (New York: Norton \& Company, 2006: 671-702), 692

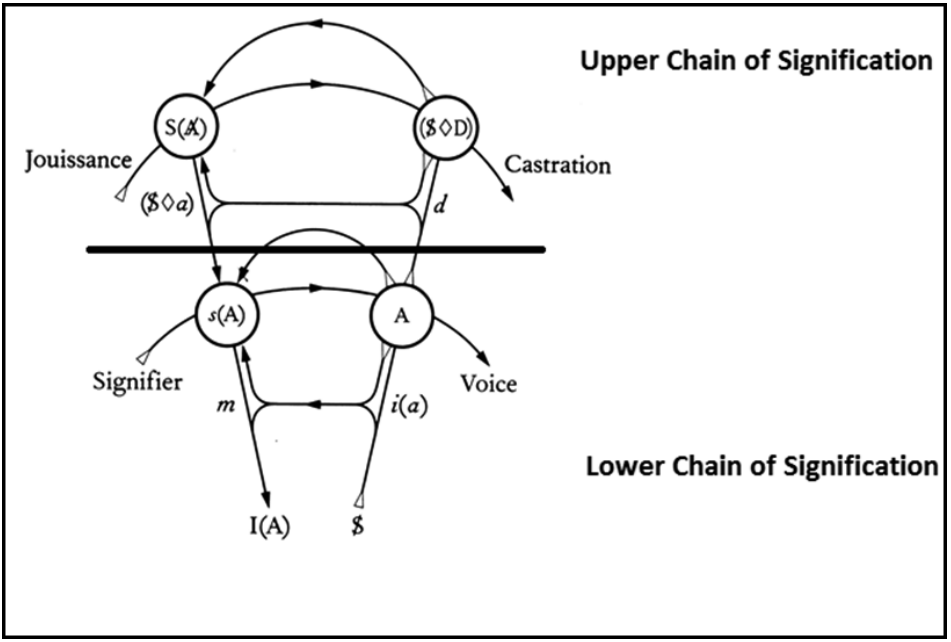


Usually, the verbalization of the phallus within the unconscious is initiated by a single signifier which is then formed into a coherent statement - S(A) - and after that, is expressed by the Other - A - into the physical interaction with one's environment by the means of the voice (see figure 1). This is the representation of the unobstructed articulation of the phallus with respect to the lower chain of signification (Lacan, 2006A 684-685).

However, the phallus may be structurally more complicated; therefore, Lacan included the upper chain of signification. Whenever the Other, which constitutes the locus of language, is dissatisfied with the unconscious articulation of the phallus, it has to be automatically re-evaluated within the upper chain of signification. The Other, then, formulates a question pertaining to what is desired; however, with respect to the subsequent modifications which have to be made in order to articulate the phallus in discourse. These modifications go as follows: when the phallus is unable to articulate itself, the Other formulates a question by the means of what Lacan calls the treasuretrove of signifiers $-\$ \diamond \mathrm{D}$ - which is the linguistic equipment of the Other that conveys meaning. After that, the question is answered - S(A $)$ - thus re-examined and reformulated into a statement again - S(A). This reformulation is where the whole chain of signification closes itself, and is subjected to the whole rigorous process of articulation again until the phallus - the desired - is fully and consciously articulated (69o-691).

The focus of this paper is intended to be put on the phenomenon of writer's block, and it is important to note how a writer's phallus manifests itself within the chain of signification. When the aforementioned chain of signification is slightly modified, it has the capacity to clarify the background behind the illusive phenomenon of writer's block. Jacques Lacan draws not only on psychoanalytical terminology but creates an interdisciplinary psycho-linguistic framework which provides ample opportunity for the study of one's sudden, and often inexplicable, inability to write. 
Figure 2. The modified chain of signification with respect to writer's block.

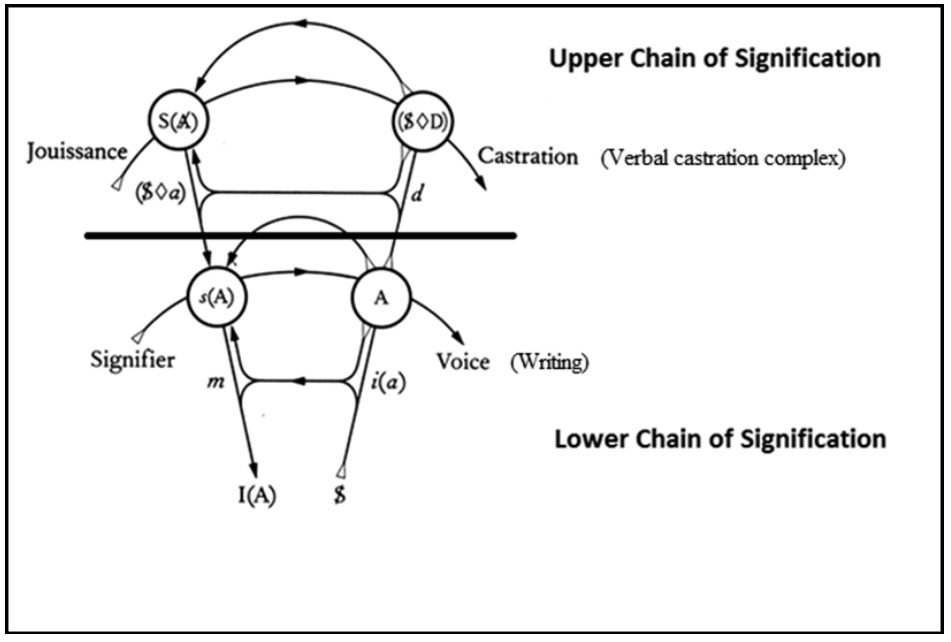

People tend to express themselves via using language; however, authors are persons of letters, and their primary conduit for viewing the universe, not just ours but the fictional as well, is discourse in its written form. Writers seem to be different in many respects when it comes to Lacan's view of articulating the phallus. It is so because the desired objects of writers are composed of words. Be it a poem, a novel, or a play, the resultant product of their desire is a composition which is created purely out of written discourse.

Writers, same as the rest of humanity, are not excluded from the intricacies of the chain of signification which each and every human being must follow in order to maintain the ability to satisfy their needs. With authors it is much more prominent. When a writer creates a story, $\mathrm{s} /$ he follows the aforementioned chain of signification, and the subsequent production of the symbolic representations of utterances. When problems occur in such a setting, it may have frustrating consequences.

The entanglement within the chain of signification described above also happens with writers; however, when this sequence recurs over and over again, the producer of the text becomes gradually frustrated. This frustration is described by Lacan as "jouissance" (Lacan, 2006A 694).

The term jouissance describes the "beyond pleasure principle". Pleasure is something which brings gratification by satisfying the phallus one craves. 
Writers are given pleasure by creating literature which means that they are tied to expressing themselves through language more deeply. Nevertheless, as the aforementioned cycle is constantly repeated, the idea of someone creating writing repeatedly passes from the Other to the treasuretrove of signifiers, and afterwards, closes the signifying chain which is re-evaluated. If the Other is then dissatisfied, the process is reiterated. The creation of writing is a pleasurable activity but if repeated a sufficient number of times without a satisfying close, jouissance inevitably takes hold, and the pleasure becomes pain which, paradoxically, arises from too much pleasure. This pain is quickly transformed into frustration with one's own inability to articulate the phallus, and subsequently, it is transposed into anxiety.

In figure 1, Lacan proposes that the final product of the unobstructed chain of signification is the voice. The voice is indeed one of the end products of this psycho-linguistic model of satisfying one's desire; however, an utterance is not the only output of one's unconscious. In the case of writers, it is the starvation for linguistic perfection and the creation of a valuable literary artefact that stand at the core of this seemingly perpetual chain. The end product of a writer's unconscious is not voice, but writing, hence the modification in figure 2.

The other modification in the second graph had to be made in order to explain what the phenomenon of writer's block truly is. When the chain of signification in one's own unconscious is repeatedly denied closure, and jouissance takes hold of one's psyche, there has to be a way out of this conundrum which must take place in the individual's consciousness. The aforementioned voice/writing is one option of a conscious emergence of the signifier which is strongly desired. The other output, according to Lacan's graph, constitutes castration.

As Lacan states, "what is not a myth, although Freud formulated it just as early on as he formulated the Oedipus myth, is the castration complex" (Lacan, 2006A 695). Sigmund Freud was indeed the first one to propose castration; however, in terms of his psychoanalysis, castration appears when a child becomes aware of people's genitalia (Freud, 1954 52), which leads to the emergence of the well-known Oedipus complex. Freud thus ties castration only to its physical properties. Nevertheless, in the context of the psycholinguistic model proposed by Lacan, the castration complex is tied to the chain of signification itself. It represents the complete and utter inability to articulate one's phallus, therefore, the desired. Whenever jouissance takes hold of the chain of signification within one's unconscious, it gradually moves 
the unarticulated signifier into the conscious mind because a suitable close of the signifying chain is not reached. Thus the resultant castration has to be reformulated into the verbal castration complex.

The verbal castration complex is what stands at the heart of this article. It stands for the concrete manifestation of writer's block. The blank page which a writer faces, and is subsequently unable to fill, constitutes the embodiment, the tangible proof of the manifestation of anxiety brought on to a writer's conscious mind from his subconscious via the system described above. Anxiety is a combination of the feelings of loss, frustration, and complete alienation from the phallus which, in this case, is the desired written work of art.

Literature comprises of an author's reflection of the real world. Although people in general perceive reality in terms of language, again, with writers it is much more prominent. It is because they describe the whole of extralinguistic reality linguistically. For them, language is the only reliable medium through which to gain understanding of the world. This theorem opens the door to a different approach in explaining verbal castration. This view of the world, limited to the perception of reality chiefly through words, is a very constrictive way of thinking, and that is what makes writers prone to succumbing to the verbal castration complex. Decoding reality through symbols, thus subsequently making reality synonymous with the written language, directly points to writer's block.

\section{The Fictional is the Impossible}

Contemporary fiction tends to deviate very strongly from the conventions of literature because of its "anti-frame" stance. Before postmodernist fiction, writers exhibited a tendency to establish a firm barrier between fiction and reality because of a strong presence of a system. This system represents the ephemeral and ever-elusive framework brought to the foreground by a structuralist way of thinking. Systems were perceived as an integral part of every research area, and were believed to be the bearers of all the answers buried deep within the recesses of their own structures.

However, as Derrida pointed out in his lecture "Structure, Sign and Play in the Discourse of Human Sciences", the sole accumulation of data becomes simply insufficient for explaining every given variable within a certain system. As Derrida explained it, "the whole history of the concept of structure, before the rupture $[\ldots]$ must be thought of as a series of substitutions of center 
for center, as a linked chain of determinations of the center" $\left(3^{6}\right)$. In short, a structure is defined by its centre that stands for the core concept around which each and every piece of knowledge inside the given system centres. According to Derrida, this poses a problem because the core concept of a system is never fully defined and it is impossible to do so in the framework of only one given system. Derrida thus proposes a solution in the form of what he calls "freeplay". In essence, freeplay is the way out of this conundrum because it allows a trans-systematic approach to gaining knowledge. It allows for an accumulation of data from a different system in order to explain the core concept of the former system.

This call for an interdisciplinary study between systems is what stands at the centre of postmodernist literature itself. Derrida's suggestion directly leads to what Patricia Waugh calls "frame-breaking" with respect to a tendency described in her book Metafiction: The Theory and Practice of Self-Conscious Fiction. According to Waugh, "contemporary metafiction, in particular, foregrounds 'framing' as a problem, examining frame procedures in the construction of the real world and of novels. The first problem it poses, of course, is: what is a 'frame" (28)?

To define a frame means two things. The first imperative is to define the centre of a particular frame. The second is to accurately identify its borders. Identifying and describing the centre of a structure is, as Derrida keeps insisting, impossible without attempting to find answers within the structure of another system. To identify the system's border means to delineate the boundary of a given structure. When it comes to fiction, the centre as well as the borders of literature itself are emptied. It is so because it is extremely difficult to pinpoint what literature at its core is, and where exactly its boundary with respect to extralinguistic reality is.

This is the reason for writers to have progressively turned to metafictional practice in writing, and in the process of employing metafiction within their work they simultaneously imply what Waugh calls "frame-breaking". Metafiction is what stands at the core of postmodernist fiction; it is the practice which enables authors to raise the status of writing being mere fiction, and, in a sense, level it with reality.

It has been established that writers of fiction in general are the ones most prone to the verbal castration complex proposed by Jacques Lacan. Although their way of perceiving the world chiefly through symbols is in itself constrictive, contemporary writers such as Paul Auster, who very frequently encompass elements of metafictional practice in their writing, are unique 
cases when examining their work in the confines of Lacanian post-structuralist psychoanalysis. Not only are they writers and thus perceive reality solely through their linguistic apparatus embedded within their psyche, they also employ the core principles of metafiction. Metafiction is the phenomenon which complicates but, at the same time, deepens the link between writer's block and the aforementioned chain of signification.

With respect to the phenomenon of writer's block, using metafiction in one's work of fiction may become dangerous territory. It is so because not only is the metafictional writer, same as any other writer, liable to entangle him/herself within the chain of signification, experiencing symptoms which one exhibits when the chain of signification is repeatedly denied closure, but this very event may be further entangled with another one of Lacan's premises - the real is the impossible.

Because writers who use metafiction in their writing attempt to level fictional reality with the extralinguistic reality they tend to view the two realities as synonymous. Thus, not only do they perceive extralinguistic reality in terms of their unconscious being structured like language, but by raising the degree of reality of fiction itself, the frustration, and the subsequent verbal castration which becomes imminent when a writer becomes entangled within the bounds of the chain of signification is thus greatly deepened. This deepening of anxiety felt by a writer experiencing writer's block is caused by one's unconscious realization that the real is the impossible. In addition, by levelling fiction with reality, the fictional becomes the impossible as well. Thus, a paradox is formed. On one hand, reality is impossible to grasp by the means of using language; on the other hand, fiction itself becomes impossible to capture by using language as well. Therefore, what a writer is left with is complete and utter nothingness which is reflected in Lacan's notion of the verbal castration complex.

\section{How Copious Writing Can Be}

In Freudian psychoanalysis, the castration complex is the result of unfulfilled oedipal desires. Simply put, it is the desire to sleep with the mother, and kill the father. In Lacan's viewpoint "castration is the punishment for incest" (Lacan, 2006B 576). However, although Lacan agrees with Freud on this premise, his psychoanalysis is also connected to the aforementioned psycholinguistic model of the phallus's articulation. A question thus arises, and is 
formulated: How do oedipal desires manifest themselves with respect to the chain of signification, and language in general?

The answer to this question is very important because Lacan's view of psychoanalytic discourse stems from a post-structuralist approach to psychoanalysis as such. His central premise is that the unconscious is structured like language which decentralizes the traditional notion of the unconscious being at the centre of this particular system. What Lacan proposes instead is a composite consisting of Freudian psychoanalytic inquiry mixed with the properties of language. Lacan does not reject any of the core concepts inherent to psychoanalysis; therefore, the notions which are tied together with Freudian castration complex must necessarily be reformulated.

Incest constitutes the desire to sleep with one's mother. In early childhood, when the child is not yet able to articulate the phallus by the means of the Other, the mother serves as a substitute for the Other which represents the locus of language that has not yet developed into a fully functioning drive. With respect to written discourse, writers, though fully in command of their Other, cling to the written language and compose their desired object (literature) out of words not only out of the treasuretrove of signifiers embedded in the Other, but also through what post-structuralist theorists call intertextuality.

According to Kristeva, who coined the term, intertextuality is "a permutation of texts [where] in the space of a given text, several utterances, taken from other texts, intersect and neutralize one another" (36). Intertextuality is a phenomenon heavily influenced by Lacanian post-structuralist psychoanalysis, and it constitutes an inalienable part of the production of writing. Writers are often avid readers of literature, and some of what they read becomes an integral part of the treasuretrove of signifiers embedded within the Other. These utterances are a reproduction and redistribution of the signifiers previously conceived by other writers, and they make up an indispensable part of a writer's production of literature.

This realization partially contradicts Lacan's notion of language inhabiting one's unconscious. Although, in terms of intertextuality, including intertextual relations in one's work is mostly an unconscious act, the very fact that these utterances are taken over from sources which are outside the realm of the Other, points to the locus of language being not entirely part of one's unconscious but extralinguistic reality as well. Therefore, it can be concluded that the part of written discourse which is outside the Other is helping a writer to articulate the phallus as well. The written discourse is thus, to a greater degree, 
a substitute for the Other, and can become synonymous with the figure of the mother during one's early childhood.

This idea opens the door to the exploration of incestuous desires with respect to post-structuralist psychoanalysis. The castration complex is the direct result of oedipal desires, the core of which is the desire to have sex with one's own mother. When the mother is finally substituted for the part of written discourse which is outside of the Other, the only thing left to explain is the sole act of sexual relations in terms of the act of writing. When it is taken into account that intertextual discourse functions as a substitute for the Other, the act of sex, therefore, the act of physical reproduction functions as a metaphorical image of the unconscious reproduction of signifiers from other writers. However, that in itself resembles the regular process of creating literature and does not yet lead to the verbal castration complex which is also known as writer's block.

Having laid the foundation for the inner workings of writer's block, the following pages of this paper will be devoted to the reflection of this phenomenon as portrayed by Paul Auster in his novel Oracle Night. Auster has been chosen due to the fact that he frequently employs metafictional practice in his writing, implicitly explores a writer's use of intertextual references, and also uses the character of a writer experiencing and struggling with writer's block in order to demystify its origins which, in combination with Lacanian poststructuralist psychoanalysis, offers an interesting insight into the exploration of the various manifestations of one's inability to write.

\section{Paul Auster's Oracle Night - An Account of Before, During, and After Writer's Block}

The journey from unconsciously using intertextual relations in one's writing to the emergence of verbal castration is very well reflected in one of Paul Auster's metafictional novels Oracle Night, which appears to be firmly "rooted in a theory that is inspired by Jacques Lacan: intersubjectivity and the dynamics of lack and desire" (Simonsen 87). Auster's depiction of the inner workings of a writer's psyche with respect to the emergence of writer's block, through the exploration of the devastating consequences of one's entanglement within the chain of signification is what stands at the heart of Oracle Night. This novel centres on a character called Sidney Orr who is a moderately successful 
fiction writer. At the beginning, it is revealed that he suffers from a disease which nearly killed him and has left its mark in the form of an impairment of his bodily functions. This disease, and his subsequent miraculous recovery leaves him and his wife in financial straits, and Orr is thus, partly against his will, pushed to writing again as his wife constitutes the sole breadwinner of the family. In the course of the story, the reader is introduced to Orr's biggest problem which is the gradual onset of writer's block. Writer's block is presented by Auster as a result of exterior events which are grounded in physical reality. Orr's physical impairment, the desperate need for money, and his injured male ego are all presented as the sole symptoms for his later fully manifested inability to write. Orr thus becomes a mere pawn in the hands of fate, or at least, so it seems to a casual observer.

Auster's and, consequently, Orr's insistence on the external events being the chief cause of writer's block are expressed through Orr fuelling his superstitions. At the beginning of the novel, Orr buys a blue Portuguese notebook from a proprietor of a shop named Chang. The notebook is presented as an object of fetish, for Orr describes it as a thing which is capable of bringing him into realms of ecstasy: "I can't explain why it should have been so, but I found those dimensions [of the notebook] deeply satisfying, and when I held the notebook in my hands for the first time, I felt something akin to physical pleasure, a rush of a sudden, incomprehensible well-being" (6). This attraction to an inanimate object appears to be characteristic of the thing sports figures do with seemingly random objects which they believe will bring them luck. In the case of Orr, who is a writer, his belief that the Portuguese notebook will bring him luck is evident from the beginning. After bringing it home with him, he experiences a rush of inspiration, and immediately comes up with a story which he remembers mulling over with a friend of his, a very successful writer, John Trause. Orr's words "came quickly, smoothly, without seeming to demand much effort. [He] found that surprising, but as long as [he] kept [his] hand moving from left to right, the next word always seemed to be there, waiting to come out of the pen" (14-15). This streak of Orr's is going on for quite some time until he reaches a dead end. Orr "is reduced to a solipsism which he unwittingly dramatizes by locking his fictional creation Nick Bowen in the underground room with no plausible means of escape" (Peacock 72).

At this point of the story, Orr faces a wall: "All I had accomplished was to back myself into a corner. Maybe there was a way out, but for the time being I couldn't see one. The only thing I could see that morning was my 
hapless little man-sitting in the darkness of his underground room, waiting for someone to rescue him" (109). Orr's sudden, and seemingly inexplicable writer's block is rationalized by Orr in the following lines:

Perhaps that was what John had been referring to when he spoke of the 'cruelty' of the Portuguese notebooks. You flew along in them for a while, borne away by a feeling of your own power, a mental Superman speeding through a bright blue sky with your cape flapping behind you, and then, without any warning, you came crashing down to earth. (109)

The "cruelty" of the Portuguese notebook Orr refers to is, again, akin to superstition. At first, the notebook was alluring, and the sole fact that he owned it and wrote into it, gave him the illusion of control over the events in his life. However, the aforementioned external factors pertaining to his developing writer's block are also later attributed to the notebook which becomes a personification of fate which rules over his life.

\section{"Beyond the Other Principle"}

However tied to the external factors Orr's attempts at writing are, the structure and impact of a writer's psyche upon his/her creation should not be omitted from this equation. "The paratextual tale that flickers to life in Orr's blue notebook reflects his preoccupation, perhaps at first subconscious, with the constant nearness of that void" (Patteson 120). In Lacanian terms, what Orr experiences at the beginning when he tries to articulate the much desired (a novel) is the perfectly functioning chain of signification. Orr's Other is fully satisfied with the gradual articulation of the signifiers which arise from the treasuretrove itself. It is when Orr is consciously confronted with what lies beyond his Other that he begins to experience what every writer dreads - the verbal castration complex.

As it has been mentioned, from a post-structuralist psychoanalytical standpoint, writing consists of two distinct parts. The first one is represented by the successful completion of the chain of signification which is the basis for the production of writing, thus the articulation of the phallus. However, the intertextual relations, with respect to writer's block in particular, cannot be discounted. It is one of the premises of this article that the internal factors (the 
Other), and the external factors (intertextual relations) are both interlinked and are both responsible for the articulation of the phallus when it comes to writers.

Orr's blame which foolishly falls onto the Portuguese notebook is misdirected, and Lacan himself would be very quick to point this out. This is where the foundation of Orr's idea for "his" novel comes to play. As Orr contemplates the basis for the novel he is attempting to write in his notebook, he thinks of "an anecdote in one of Dashiell Hammett's books. [He is] referring to the Flitcraft episode in the seventh chapter of The Maltese Falcon, the curious parable that Sam Spade tells Brigid O'Shaughnessy about the man who walks away from his life and disappears" (12-13). Instead of trying to manifest an original idea, Orr takes over this segment from The Maltese Falcon. The idea is solid at first, the chain of signification of Orr's Other is flawless. Orr's unconscious is toying with and reforming the intertextual reference to Flitcraft. His idea is to make this episode into a fully blown novel. However, after he puts his protagonist into a locked dark room, he finds himself at an inexplicable loss for words.

Until then, writing in the blue notebook had given me nothing but pleasure, a soaring, manic sense of fulfillment. Words had rushed out of me as though I were taking dictation, transcribing sentences from a voice that spoke in the crystalline language of dreams, nightmares, and unfettered thoughts. On the morning of September 20, however, two days after the day in question, that voice suddenly went silent. I opened the notebook, and when I glanced down at the page in front of me, I realized that I was lost, that I didn't know what I was doing anymore. I had put Bowen into the room. I had locked the door and turned out the light, and now I didn't have the faintest idea of how to get him out of there. (108)

This sudden realization of him not being able to complete the story and find suitable closure for his character is reminiscent of the entanglement within the chain of signification.

As Herzogenrath points out, "[b]oth literature and scientific discourses such as psychoanalysis and philosophy are based on 'texts', are narratives in the sense of being essential constituents of both creating and understanding 'reality" (5). However, nothing that comes out of the treasuretrove of signifiers seems to reinstate that feeling of reality through whatever form of discourse. 
Nothing gives Orr's Other gratification, thus forcing the articulation of the phallus to entangle itself, and subsequently, as Auster notes, the act of writing which initially gave Orr so much pleasure, suddenly turns to jouissance.

The emergence of jouissance within the chain of signification is nothing more and nothing less than the gradual manifestation of the verbal castration complex which begins to plague Orr throughout the whole story. Nevertheless, the cause of his loss for words is yet to be analysed. Because the unconscious reproduction of a preexisting text has been described in terms of intertextuality and is perfectly common in the production of written utterances, it is the conscious reproduction that seems to be the cause of the verbal castration complex.

Being a writer, Orr is fully capable of coming up with a way out for his character but the reason he gives for not pushing on with his novel is more than perplexing. "Dozens of solutions sprang to mind, but they all seemed trite, mechanical, dull. Trapping Nick in the underground bomb shelter was a compelling idea to me - both terrifying and mysterious, beyond all rational explanation - and I didn't want to let go of it" (108). This idea of Orr's character being trapped underground with no possible way out which would satisfy Orr's chain of signification into the articulation of the phallus, is the reason for his entanglement within the chain of signification itself. It is the point at which Orr's conscious mind grasps what his unconscious has been creating; that is, a mere reproduction of Hammett's original idea. Orr then continues by saying that "once I'd pushed the story in that direction, I had diverged from the original premise of the exercise. My hero was no longer walking the same path that Flitcraft had followed" (108). It seems here that Orr's unconscious simply flips a switch, and moves the thought of him using intertextual relations throughout the whole writing of his novel into his consciousness.

This leads to an interesting conclusion. Orr's unconscious simply boycotts the reproduction of intertextual references within his own writing, and transposes this fact into his conscious mind, which results in the emergence of writer's block. In other words, he is unable to button down "the subject's signifying chain and thereby allowing it to 'make sense"' (Herzogenrath 46). This points to the fact that writer's block truly is just a manifestation of one's entanglement within the chain of signification, and Auster's exploration of this phenomenon suggests that the cause for this lies within a writer's conscious realization that the articulation of the phallus, thus the production of the 
desired piece of writing, is based on the reproduction of preconceived written utterances. Intertextual references are, therefore, the source of the jouissance felt by the writer experiencing the onset of writer's block.

Auster's protagonist consciously realizes what his unconscious was coping with up to this point; that is, the fact that his whole attempt at writing a novel based on not just the story of another writer, but the overall feeling encompassed within that story, is merely a copious transposition of words which have already been uttered. Auster thus practically explores the previously mentioned incestuous relations with respect to written discourse.

Incest in writing; the copying of signifiers from another writer, directly leads to the verbal castration complex under the patronage of the conscious realization of this very act. In addition, throughout Oracle Night, Auster offers further evidence to back this claim. During Orr's struggle with the novel based on Hammett's The Maltese Falcon, Orr is contacted by an agent to write a movie script based on H.G. Wells's novella The Time Machine. Orr's attitude towards writing a script for the novella is apparent straight from the beginning. He views Wells's work as "pure rubbish, [...] fantasy of the lowest order" (127). In spite of that, Orr quickly scribbles the idea for the movie script and sends it to the director of the movie who is a great admirer of his.

Later in the story, Orr's script is rejected, and so is the money he was promised for writing this piece. Orr's casual attitude towards this offer suggests a greater degree of detachment from the physical world, and thus the financial trouble in which he and his wife are. He only agrees to write the script for the sake of some distant calling of responsibility he feels towards his family. However, being a writer, Orr seems to purposefully and pre-emptively sabotage the project and his own financial security, again, because of the conscious realization of his psyche that the act of rewriting Wells's novel premeditatedly leads to nothing but a rehash of something that was written beforehand. What deviates from the pattern which leads to writer's block in the case of Hammett's The Maltese Falcon, is that in the case of Wells's The Time Machine, Orr finishes the script while fully and consciously realizing that he has merely expanded on the pre-existing intertextual relations. The fact that the script is finished suggests that jouissance and the resultant writer's block is imminent only while the writer is using intertextual references towards which s/he has a positive attitude. When it is the other way round, consciously reproducing preconceived written utterances, it allows for the completion of the phallus but with the same result exhibited by a writer with the verbal 
castration complex. Orr's opinion of The Time Machine allows him to craft the aforementioned script but the result is equivalent to the inability to articulate the phallus because, in both cases, it all amounts to nothing.

\section{Acting out of Frustration}

The cause as well as the manifestation of the phenomenon of writer's block as presented in Auster's Oracle Night has been dealt with. What remains to explore are the ramifications that verbal castration may have upon an individual and his/her surroundings. What constitutes a writer's phallus is what is perceived as literature in any form possible. Literature as such is a part of the cultural expression of human beings; it is as much about the aesthetic appeal as it is about creating something worthy. In essence, it is about the zeal of an individual to make at least a dent in the cultural Zeitgeist. The analysis of Lacan's notion of the obstruction in the signifying chain in one's unconscious is inextricably linked to another interesting phenomenon, found in the work of his predecessor and the father of psychoanalysis, Sigmund Freud. Similarly to Auster's Oracle Night being synchronized with Lacan's concepts which explain the very basis of writer's block, in line with the psychoanalytical inquiry, the novel also explores the ramifications of one's entanglement in the signifying chain though the use of Freud's theory of the creation of culture.

According to Freudian psychoanalysis, culture is a phenomenon which results from the perpetual tension between the individual and society. For Freud, the individual is structurally vicious and civilization has the mission to tame him/her. The price to pay for collective happiness (civilization) is individual unhappiness, thus forcing the individual to delay, or repress direct gratification of instincts. Society enforces restrictive actions upon an individual included within that society, and as a result, the individual is then forced to conform. This, however, may have rather devastating consequences, for the natural human instincts which reside within one's $I d$ are the instinct of love, and the instinct of aggression. These two basic human instincts are both repressed by society's inclusion of moral and social norms. This repression leads to what Freud calls sublimation.

Sublimation of instinct is an especially conspicuous feature of cultural development; it is what makes it possible for higher psychical activities, 
scientific, artistic, or ideological, to play such an important part in civilized life. Sublimation is a vicissitude which has been forced upon the instincts entirely by civilization. (Freud, 2010 51-52)

What Freud proposes is that there seems to be a kind of suppression of instincts which actually serves a purpose. It does not lead to frustration or anxiety if an individual who is a part of society is capable of creating something worthwhile. Creating any form of culture while advancing its development requires a tremendous amount of energy. This energy seems to be naturally channelled from the aforementioned suppression of instinctual energy and is, therefore, sublimated into the creation of culture.

The creation of culture, in this case, literature, is also based on the Lacanian chain of signification. There is no universal satisfaction without the phallus being fully articulated. When the phallus is repeatedly not articulated and jouissance is introduced into the mix, the verbal castration is thus imminent. This automatically precludes the stream of suppressed instinctual energy to reach and create the intended phallus, and thus, renders this energy stream ineffective with respect to the writer's intent. When the creation of culture is denied by the inability to articulate the phallus the stream of suppressed instinctual energy is thus redirected and reversed. It then goes back to the basis of primal human instincts - the $I d$, and causes writers experiencing verbal castration complex to act out in accordance with their instincts.

Auster's skilful portrayal of this very phenomenon is also a part of his Oracle Night. Auster very vividly explores what happens to a writer's psyche when he/she is denied the opportunity to articulate the phallus. There are two distinct episodes which occur after jouissance takes hold of Orr's psyche; that is, the moment when his conscious mind grasps that what he created was just the interlinking of various intertextual references into one composite based on Hammett's novel The Maltese Falcon. Later on in the story, Orr meets with Chang, now the former proprietor of the shop where Orr bought his Portuguese notebook. Chang has decided to go into a different business, and he takes Orr to a bizarre combination of a bar and a brothel. Chang introduces Orr to one of the prostitutes in the establishment, and Orr is immediately swayed by her beauty. He notes that "I wanted to get up and leave before I got myself into trouble, but I couldn't move. The girl was too much, and I couldn't stop looking at her" (151). Orr is indeed unable to stop himself, and although it might be argued that he was under the influence of alcohol at the time, he also remembers that he "was sober enough to realize that [he] 
was travelling down the road to perdition, but [he] didn't let that stop [him]" $(152)$. He then does not leave the bar, and is taken into a private booth where Chang's prostitute orally satisfies him.

Sidney Orr, a character who is portrayed as a devoted husband, a generally good person, and someone who is already wracked with guilt because he is unable to support his wife, "in the span of thirty-six short hours" goes "from being a self-righteous defender of moral certainties to an abject, guiltridden husband" (152). This development is not further commented on, and is presented as wildly inexplicable. The other episode mentioned earlier happens after the incident with the prostitute. Orr is again confronted with Chang in his newly founded establishment. Chang is angry at him for running out on him after Orr's escapade at the bar/brothel, and they both get into a heated discussion which is provoked by Orr. It then results in a fight where Chang beats Orr, who then walks away.

Again, this incident is not commented on in any way. Both, the infidelity, and the random fight Orr picked with Chang, are preceded by Orr's failures as a writer to express his desires in writing. The sublimation of instinctual energy is repressed by Orr's inability to write, and this fact makes him susceptible to the ever-prevailing $I d$ where his instincts reside. His puzzling fling at the bar, and his mystifying fight with Chang, both serve as an account of what might happen to a writer when his/her sole purpose in the world, the thing s/he loves the most, is denied to him/her by his/her own conscious mind. Both episodes accurately mirror the reversal of instinctual energy, and its subsequent outburst into the freeing of the love and aggression instincts in Orr's unconscious.

\section{Conclusion}

The phenomenon of writer's block is usually looked upon as a reflection of events which transpire within the scope of extralinguistic reality. However, the opposite may also be the truth. As this analysis has shown, the verbal castration complex, the inability to articulate the phallus; therefore, writer's block, is first and foremost a linguistic problem. It may stem from an obstruction which becomes manifest within the chain of signification. This obstruction appears in the form of the entanglement of the signifier within one's signifying chain. This paper has also shown that whenever this process is repeated, jouissance, the pain which arises from too much pleasure, takes hold of one's unconscious, and 
is subsequently let out of the signifying chain in the articulation's malformation which constitutes the basis for the phenomenon of writer's block.

This process is described and explored in the selected novel of a postmodernist writer, Paul Auster. In Auster's work, there are distinct patterns pertaining to the inability to articulate one's phallus which are in accordance with the notions proposed by the French post-structuralist psychoanalyst, Jacques Lacan. First of all, Auster points to the psychological element of jouissance as being the chief cause of the onset of writer's block. However, the entanglement within the chain of signification does not appear to be the only cause of writer's block. Along with the element of jouissance which represents a writer's conscious realization that $\mathrm{s} / \mathrm{he}$ is merely copying and subsequently remodifying signifiers from another writer, Auster skilfully mirrors the two chief causes of verbal castration complex which represent the obstruction in the signifying chain, and the conscious realization of one's use of intertextual references in one's production of literature. In the case of Auster's protagonist in Oracle Night, Sidney Orr, it is his attempts at writing a novel while using the idea as well as the overall feeling of Dashiell Hammett's novel, The Maltese Falcon. Orr's conscious realization of this fact leads to his inability to write immediately after this understanding. In Orr's case, it is the experienced feeling of jouissance which leads to the onset of writer's block triggered by him realizing that what he has produced was a mere reproduction of someone else's fiction.

Furthermore, Auster's character is at first presented as a person of moral integrity but under the pressure of his inability to articulate the phallus, he slowly crumbles and regresses into the indulgence of his instincts. Auster is in concordance with another psychoanalyst, Sigmund Freud, and Lacan as well, when he practically examines what happens to a writer when he is denied the creation of culture. The energy used in the creation of cultural artefacts is redirected and channelled back into the instincts of love and anger, thus morally corrupting Auster's main character.

\section{Notes}

1. See Rose, 1984; Hall, 1994, Lonka et al., 2014; Sanders-Reio, Alexander, Reio \& Newman, 2014, among others.

2. Oracle Night is, by far, not the only source of such claims. Auster has, on several occasions confessed to have gone through a period of writer's block, for instance, in his memoir Hand to Mouth: A Chronicle of Early Failure (1997), where he writes: "In my late twenties and early thirties, I went through a period of several years when everything I touched 
turned to failure. My marriage ended in divorce, my work as a writer foundered, and I was overwhelmed by money problems [...] I was an ex-writer, a writer who wrote only for the satisfaction of crumbling up paper and throwing it in the garbage" (199). He has also embodied the experience in his lesser known prose-poem White Spaces (1980), which marks the period when he stopped writing poetry and started writing fiction.

\section{Works Cited}

Auster, Paul. Oracle Night. London: Faber and Faber Limited, 2004. Print.

---. Hand to Mouth: A Chronicle of Early Failure. London: Faber and Faber, 1997. Print.

Derrida, Jacques. "Structure, Sign, and Play in the Human Sciences." Twentieth Century Literary Theory. Ed. Vassilis Lambropoulos and David Neal Miller. New York: State University of New York Press, 1987. Print.

Freud, Sigmund. Civilization and Its Discontents. Eastford: Martino Fine Books, 2010. Print.

--.. The Origins of Psycho-Analysis: Letters to Wilhelm Fliess, Drafts and Notes: 18871902, Ed. Marie Bonaparte, Anna Freud, Ernst Kris. New York: State University of New York Press, 1987. Print.

Hall, Caroline. Getting Down to Writing: A Students' Guide to Overcoming Writer's Block. Norfolk: Peter Francis Publishers. 1994. Print.

Herzogenrath, Bernd. The Art of Desire. Amsterdam: Rodopi, 1999. Print.

Lacan, Jacques. "The Subversion of the Subject and the Dialectic of Desire in the Freudian Unconscious." Écrits: The First Complete Edition in English. Ed. Bruce Fink. New York: Norton \& Company, 2006A. Print.

--.. "The Signification of the Phallus." Écrits: The First Complete Edition in English. Ed. Bruce Fink. New York: Norton \& Company, 2006B. Print.

Landman, Peta. Writer's Block and Its Association with Anxiety. 2016. Australian College of Applied Psychology, Master's Thesis. Web. Accessed 10 March 2019. http://www.academia.edu/25786833/Writers_block_and_its_ association_with_anxiety

Lonka, Kirsti, Angela Chow, Jenni Keskinen, Kai Hakkarainen, Niclas Sandström, \& Kirsi Pyhältö. "How to measure PhD students' conceptions of academic writing?" fournal of Writing Research, vol. 5, no. 3. 2014: 245-269. Web. Accessed 10 March 2019. http://www.jowr.org/articles/vol5_3/JoWR_ 2014_vol5_nr3_Lonka_et_al.pdf

Patteson, Richard F. "The Teller's Tale: Text and Paratext in Paul Auster's Oracle Night." Critique: Studies in Contemporary Fiction, vol. 49, no. 2. 2008: 115-130. Print. 
Peacock, James. “Signs of Grace: Paul Auster's Oracle Night." English: Fournal of the English Association, vol. 55, no. 211. 2006: 65-78. Print.

Rose, Mike. "Writer's block: The cognitive dimension." Studies in Writing \& Rhetoric. Carbondale, IL: Southern Illinois University Press, 1984. Web. Accessed 5 March 2019. http://eric.ed.gov/?id=ED248527

Sanders-Reio, Joanne, Patricia Alexander, Thomas G. Reio \& Isadore Newman. "Do students' beliefs about writing relate to their writing self-efficacy, apprehension, and performance?" Learning and Instruction, vol. 11. 2014: 1-11. Web. Accessed 5 March 2019. http://dx.doi.org/10.1016/j.learninst ruc.2014.02.001

Simonsen, Rasmus R. "Even or(r) Odd: The Game of Narration in Paul Auster's Oracle Night." American Studies in Scandinavia. Ed. Janne Lahti. Odense: University Press of Southern Denmark, 2009. Print.

Waugh, Patricia. Metafiction: The Theory and Practice of Self-Conscious Fiction. New York: Routledge, 1984. Print.

MAROŠ BUDAY is as an assistant professor at the University of Prešov, Institute of British and American Studies, Slovakia. He completed his doctoral studies at the same university by successfully defending his dissertation The Concept of Multiverse in Stephen King's and Paul Auster's Fiction. His current fields of research are postmodernist literature and American studies.

maros.buday@gmail.com 